\title{
Reversible electrochemical interface of Mg metal and conventional electrolyte enabled by intermediate adsorption
}

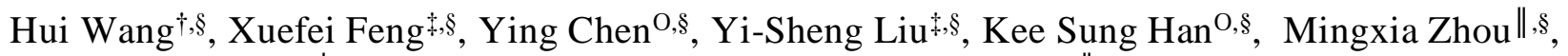
Mark H. Engelhard ${ }^{\perp}$, Vijayakumar Murugesan ${ }^{0, \S}$, Rajeev S. Assary $\|, \S$, Tianbiao Leo Liu ${ }^{\dagger}$, Wesley Henderson $^{\dagger}$, Zimin Nie ${ }^{\dagger}$, Meng Gu${ }^{\dagger}$, Jie Xiao ${ }^{\dagger}$, Chongmin Wang ${ }^{\perp}$, Kristin Persson ${ }^{\star}, \#$, Donghai Mei $^{\mathrm{O}, \mathrm{Il}}$, Ji-Guang Zhang ${ }^{\dagger, \S}$, Karl T. Mueller ${ }^{\mathrm{O}, \S}$, Jinghua Guo ${ }^{\ddagger, \S}$, Kevin Zavadil $^{\Delta, \S}$, Yuyan Shao ${ }^{*},, \S$, Jun $\operatorname{Liu}^{\dagger}$

$\dagger$ Energy \& Environment Directorate, Pacific Northwest National Laboratory, Richland, Washington 99352, USA

\$ Advanced Light Source, Lawrence Berkeley National Laboratory, Berkeley, California 94720, USA.

O Physical and Computational Sciences Directorate, Pacific Northwest National Laboratory, Richland, Washington 99352, USA

\| Materials Science Division, Argonne National Laboratory, 9700 S. Cass Avenue, Illinois 60439, USA

${ }^{\perp}$ Environmental Molecular Sciences Laboratory, Pacific Northwest National Laboratory, Richland, Washington 99352, USA

- Energy Technologies Area, Lawrence Berkeley National Laboratory, Berkeley, California 94720, USA

${ }^{\Delta}$ Material, Physical, and Chemical Sciences, Sandia National Laboratories, Albuquerque, New Mexico 87185, USA.

$\S$ Joint Center for Energy Storage Research (JCESR), Lemont Illinois 60439, USA.

\# Department of Materials Science and Engineering, University of California, Berkeley, Berkeley, California 94720, USA

*Corresponding author: yuyan.shao@pnnl.gov 


\section{Experimental Procedures}

Chemicals. Magnesium borohydride $\left(\mathrm{Mg}\left(\mathrm{BH}_{4}\right) 2,95 \%\right)$, magnesium ribbon (99.5\%), Magnesium bis(trifluoromethane-sulfonyl)imide ( $\left.\mathrm{Mg}(\mathrm{TFSI})_{2}\right)$ was purchased from Solvionic (France). Battery-grade diethylene glycol dimethyl ether (diglyme) was obtained from Novolyte Technologies, Inc. Electrolyte chemicals were further dried using $3 \AA$ molecular sieves. Asreceived $\mathrm{Mg}\left(\mathrm{BH}_{4}\right)_{2}$ was directly used. However, $\mathrm{Mg}(\mathrm{TFSI})_{2}$ was dried at $180{ }^{\circ} \mathrm{C}$ for $48 \mathrm{~h}$ in the antechamber of the glove box prior to use.

Electrochemistry. Cyclic voltammetry was conducted in a standard three-electrode cell with $\mathrm{Mg}$ ribbons as reference/counter electrodes. The working electrodes were Pt wire, glassy carbon, or stainless steel 316. The electrolytes were prepared by dissolving the salts (i.e., $\mathrm{Mg}\left(\mathrm{BH}_{4}\right)_{2}$, and $\left.\operatorname{Mg}(\mathrm{TFSI})_{2}\right)$ in the solvent diglyme. The electrochemical testing was conducted in an Ar-filled glovebox $\left(\mathrm{O} 2\right.$ and $\left.\mathrm{H}_{2} \mathrm{O}<0.1 \mathrm{ppm}\right)$. The coulombic efficiency $(\mathrm{CE})$ was calculated by dividing the charge obtained for the $\mathrm{Mg}$ stripping by the charge from the $\mathrm{Mg}$ plating.

Operando electrochemical impedance spectroscopy (EIS) Operando EIS was conducted in a three-electrode Swagelok cell (Supplementary Fig. 7) with Mg ribbons as the counter electrodes, $\mathrm{Mg}$ ribbon as the reference electrode or $\mathrm{Ag} / \mathrm{AgCl}$ as the reference electrode. The working electrodes were Pt disk or $\mathrm{Cu}$ disk. Electrochemical impedance spectroscopy measurements of these cells were carried out in the frequency range of $106-0.01 \mathrm{~Hz}$ at $30^{\circ} \mathrm{C}$ by techniques of Staircase Potentio Electrochemical Impedance Spectroscopy (SPEIS) or Potentio Electrochemical Impedance Spectroscopy (PEIS) using Biologic VMP-300.

Calculation: Distribution relaxation times (DRT) from EIS data The DRT is a useful complementary tool for the traditional equivalent circuit modeling approach of analyzing EIS data. Obtaining the DRT from EIS data is a mathematically ill posed problem. DRT data were calculated by MatlabR2017a with a toolbox of DRT-TOOLS developed by the research group of Professor Francesco Ciucci $^{1}$. DRT-TOOLS is freely available under the GNU license from the following site: https://sites.google.com/site/drttools/

Operando X-ray absorption spectroscopy (XAS): To perform operando XAS experiment, a static liquid cell was designed. The 3D model and the cross-sectional view are shown in Supplementary Fig. 7. The geometry of the liquid cell is ideal to probe the electrochemical interface through a thin Si3N4 window. Briefly, the main body of the cell was made of PEEK, which has very high resistance and chemical stability. Electrolyte of interest was loaded into the center hole and sealed with a rubber O-ring. A $100 \mathrm{~nm}$ thick $\mathrm{Si}_{3} \mathrm{~N}_{4}$ window coated with $15 \mathrm{~nm} \mathrm{Au}$ was covered on top of the electrolyte, serving as a working electrode, the size of the window is 1 $\mathrm{mm}$ (Horizontal) $\times 0.5 \mathrm{~mm}$ (Vertical). $\mathrm{Mg}$ coated Pt wire and $\mathrm{Mg}$ wire were inserted into the electrolyte, working as the counter and reference electrodes, respectively.

The operando XAS experiments were performed at beamline 8.0.1, wet-RIXS endstation at the Advanced Light Source (ALS), Lawrence Berkeley National Laboratory (LBNL). The X-ray beam size is $100 \mu \mathrm{m}$ (Horizontal) $\times 35 \mu \mathrm{m}$ (Vertical). The Mg K-edge XAS spectra were collected in Total Fluorescence Yield mode (TFY) and calibrated with a MgB2 reference sample. All the Mg K-edge spectra were collected in-situ under ultra-high vacuum and acquired continuously 
when applying different voltages using SP-200 potentiostat. Low signal-to-noise ratio should be associated with the low beam flux at the $\mathrm{Mg} \mathrm{K}$-edge (ca. $1300 \mathrm{eV}$ ) beyond the photon energy range of $80-1200 \mathrm{eV}$ at the beamline 8.0.1.

Nuclear magnetic resonance (NMR): All solution-state NMR measurements were performed on a Varian DDRS spectrometer with a $11.7 \mathrm{~T}$ magnet using a broad-band (BBO) probe. The $90^{\circ}$ pulse widths were $13.2 \mu \mathrm{s}$ for ${ }^{1} \mathrm{H}, 6.8 \mu \mathrm{s}$ for ${ }^{13} \mathrm{C}, 11.5 \mu \mathrm{s}$ for ${ }^{19} \mathrm{~F}$, and $12 \mu \mathrm{s}$ for ${ }^{11} \mathrm{~B}$. T2 relaxation time constants were measured using $\mathrm{CPMG}$ methods. ${ }^{19} \mathrm{~F}$ NMR spectra were referenced to $\mathrm{CF}_{3} \mathrm{CH}_{2} \mathrm{OH}(-77.8 \mathrm{ppm})$ and $11 \mathrm{~B}$ NMR spectra were referenced to external $\mathrm{BF}_{3}$ in ether $(0.00$ ppm).

X-ray photoelectron spectroscopy (XPS): XPS was measured on a Physical Electronics Quantum 2000 Scanning ESCA Microprobe with a 16 element multichannel detector. This system uses a focused monochromatic Al Ka X-ray $(1486.7 \mathrm{eV})$ source and a spherical section analyzer. The X-ray beam used was a $100 \mathrm{~W}, 100 \mu \mathrm{m}$ diameter beam that was rastered over a $1.3 \mathrm{~mm} \times 0.2$ $\mathrm{mm}$ rectangle on the sample. The X-ray beam is incident normal to the sample and the photoelectron detector was at $45^{\circ}$ off-normal using an analyzer angular acceptance width of $20^{\circ} \times$ $20^{\circ}$. Wide-scan data were collected using a pass energy of $117.4 \mathrm{eV}$. For the $\mathrm{Ag}_{3 \mathrm{~d}^{5 / 2}}$ line, these conditions produce FWHM of better than $1.6 \mathrm{eV}$. High energy resolution spectra were collected using a pass energy of $46.95 \mathrm{eV}$. For the $\mathrm{Ag}_{3 \mathrm{~d}^{5 / 2}}$ line, these conditions produced FWHM of better than $0.98 \mathrm{eV}$. The binding energy (BE) scale was calibrated using the $\mathrm{Cu}_{2 \mathrm{p}} \mathrm{p}^{3 / 2}$ feature at $932.62 \pm$ $0.05 \mathrm{eV}$ and $\mathrm{Au}_{4 \mathrm{f}}$ at $83.96 \pm 0.05 \mathrm{eV}$ for known standards. Before the XPS measurements, all of the samples were washed with THF and dried in the glovebox antechamber under vacuum overnight. The dried sample was tightly sealed in the Ar-filled envelope and moved into the tArfilled transition glovebox for XPS measurement.

X-Ray diffraction (XRD): XRD powder patterns were obtained using a Philips Xpert X-ray diffractometer with $\mathrm{Cu} K \alpha$ radiation at $\lambda=1.54 \AA$. Samples were sealed in a special XRD sample holder which prevents oxygen and moisture from contacting samples. Before the XRD measurements, all the samples were washed with THF and dried in the glovebox antechamber under vacuum overnight. The dried sample was tightly wrapped by the Kapton film within the XRD sample holder.

Scanning electron microscope (SEM): SEM images were collected on a JEOL 5900 scanning electron microscope equipped with an EDAX energy dispersive $\mathrm{x}$-ray spectroscopy (EDS) system. The detection limit of EDS is 0.5 atom\%. Samples were shortly exposed to air during the sample transfer from the Ar-filled envelope to the transition antechamber of SEM instrument.

DFT calculations: The interactions of $\mathrm{BH}_{4}{ }^{-}$and $\mathrm{TFSI}^{-}$anions with the $\mathrm{Mg} 0$ were studied based on density functional theory calculations using Vienna ab initio simulation package (VASP) ${ }^{2-4}$. The GGA-PBE functional ${ }^{5}$ for exchange-correlation energy and projector-augmented wave (PAW) method ${ }^{6}$ for electron-ion interaction were used in the calculations. The cutoff energy was set as $400 \mathrm{eV}$. The Brillouin-zone ${ }^{7}$ was sampled with $7 \times 7 \times 1 \mathrm{k}$-point mesh. Five $\mathrm{Mg}$ atomic layers $(5 \times 5) \mathrm{Mg}(0001)$ surface slab was used to model $\mathrm{Mg}$ anode. The bottom two layers were fixed at the $\mathrm{Mg}$ bulk position while the top three layers with adsorbate were allowed to relax during 
the geometry optimization. A height of $30 \AA$ vacuum layer was added between successive slabs to avoid unphysical periodic charge interaction. The convergence criteria for the structure optimization is the force on each atom be less than $0.02 \mathrm{eV} / \AA$. Although the instability of BH4- in vacuum present challenges for calculation of interaction energy, the as-obtained distinct difference of these interaction energies could be regarded as a supporting evidence for the preferential adsorption of $\mathrm{BH}_{4}^{-}$onto $\mathrm{Mg}$ metal than $\mathrm{TFSI}^{-}$.
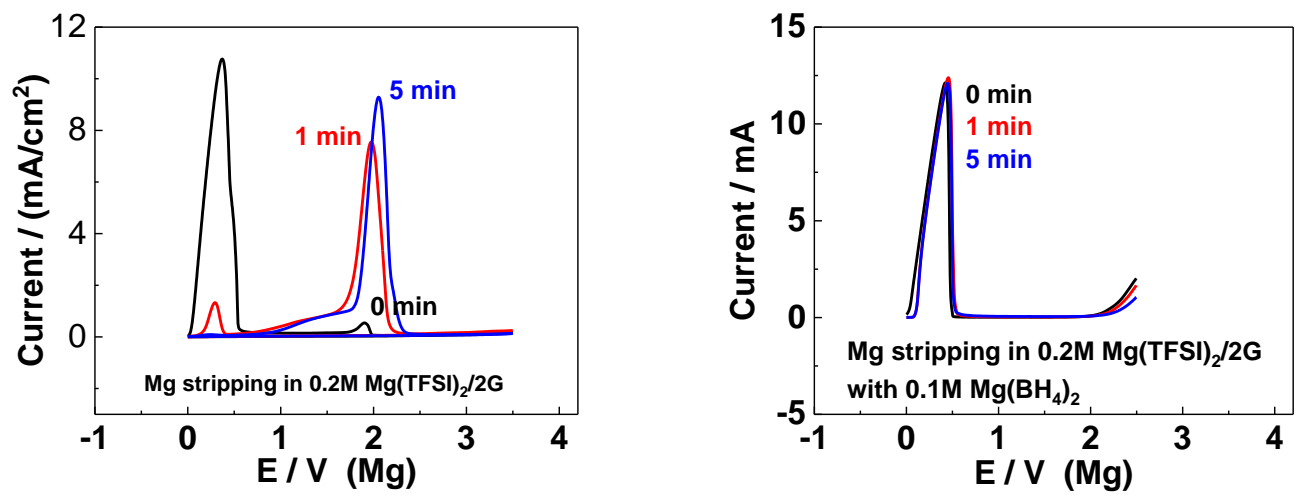

Figure S1 The stripping of fresh $\mathrm{Mg}$ metal deposition after dipping in (a) $0.2 \mathrm{M}$ $\mathrm{Mg}(\mathrm{TFSI})_{2} /$ diglyme and (b) $0.2 \mathrm{M} \mathrm{Mg}(\mathrm{TFSI})_{2} /$ diglyme with $0.1 \mathrm{M} \mathrm{Mg}\left(\mathrm{BH}_{4}\right)_{2}$ for 0,1 and 5 minutes respectively.

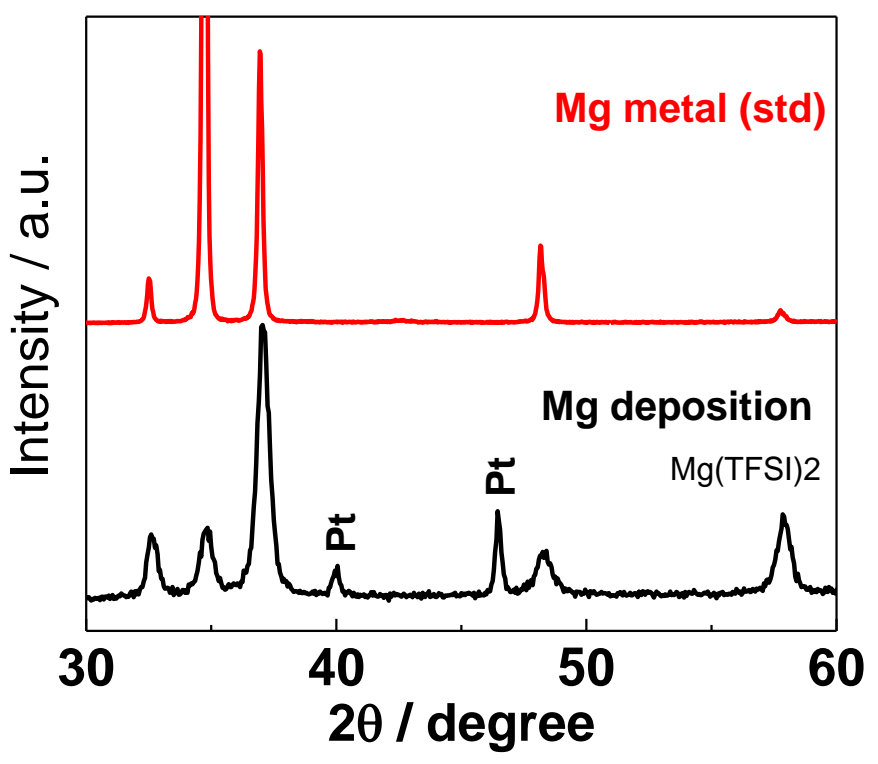

Figure S2. XRD patterns of the Mg deposition from $0.2 \mathrm{M} \mathrm{Mg(TFSI)2/diglyme.}$ 

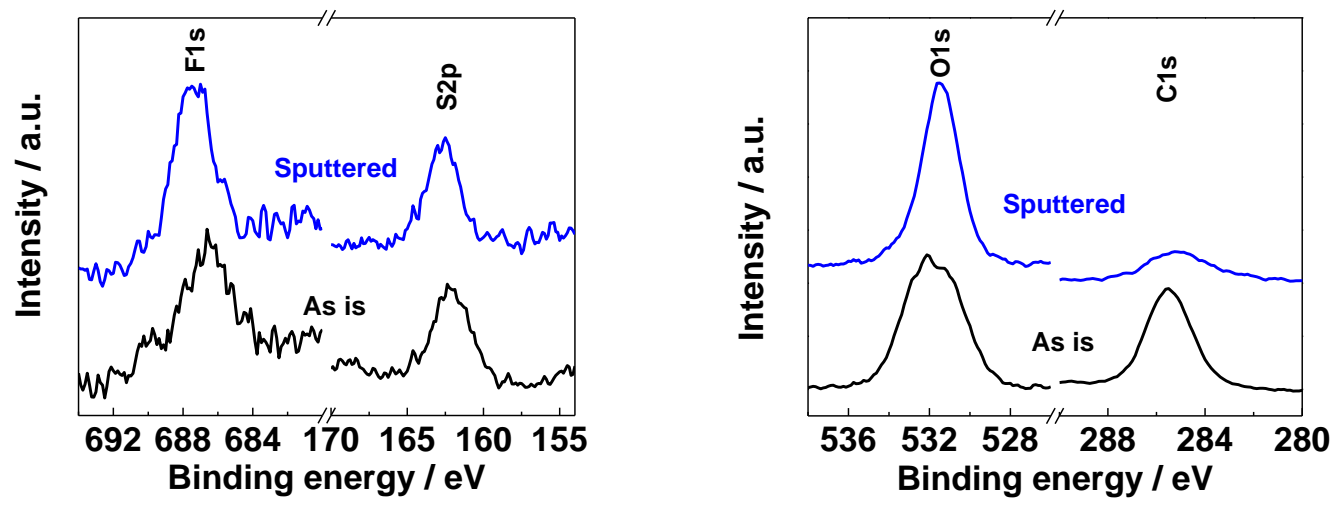

Figure S3. XPS of Mg deposition in 0.2M Mg(TFSI) 2/diglyme (F1s, S2p, C1s and O1s spectra).

Table S1. Atomic concentration (at. \%) calculated from high energy resolution photoemission spectra ( $\mathrm{Mg}$ deposition from $0.2 \mathrm{M} \mathrm{Mg}(\mathrm{TFSI})_{2} /$ diglyme).

\begin{tabular}{llllll}
\hline & $\mathrm{Mg}$ & $\mathrm{F}$ & $\mathrm{S}$ & $\mathrm{C}$ & $\mathrm{O}$ \\
\hline As-is & 6.6 & 2.1 & 2.4 & 47.7 & 41.2 \\
\hline Sputtered & 27.2 & 3.4 & 2.3 & 20.8 & 46.4 \\
\hline
\end{tabular}

XRD powder patterns (Fig. S2) for the deposited material from the $0.2 \mathrm{M}$ $\mathrm{Mg}(\mathrm{TFSI})$ /diglyme electrolyte identify the existence of $\mathrm{Mg}$ metal. An X-ray photoelectron spectroscopic (XPS) characterization of the $\mathrm{Mg}$ deposition reveals additional information (Fig. 1 b and Fig. S3). The broad $\mathrm{Mg}_{2}$ peak (actually two overlapping peaks in Fig. 1c) indicates a complicated chemistry at the Mg surface ("As is" sample) and in the bulk material (the "Sputtered" sample for which $20 \mathrm{~nm}$ was removed through $\mathrm{Ar}^{+}$sputtering), which includes signals from both $\mathrm{Mg}^{0}$ and $\mathrm{Mg}^{2+}$ compounds $^{8}$. Significant amounts of F, S, O, C are also observed in the Mg deposition (Fig. S3) and the atomic ratio of $\mathrm{F} / \mathrm{S}(\mathrm{F} / \mathrm{S}=1.0-1.5)$ calculated from high-resolution XPS (Table S1) differs significantly from that for $\mathrm{Mg}(\mathrm{TFSI})_{2}(\mathrm{~F} / \mathrm{S}=3.0)$, indicating that the $\mathrm{F}$ and $\mathrm{S}$ are not simply from surface-absorbed $\mathrm{Mg}(\mathrm{TFSI})_{2}$ salt, but rather from the decomposition products of the TFSI ${ }^{-}$anion. Previous studies ${ }^{9}$ have shown that $\mathrm{Mg}$ metal 
reacts with conventional electrolyte components (as well as trace water and $\mathrm{CO}_{2}$ in the electrolyte or glovebox) to form a surface film, and the composition of such films is similar to that on Li metal surfaces exposed to a similar environment, i.e., metal oxide, metal hydroxide, carbonate, fluoride, sulfide, and other metal compounds ${ }^{10}$. The exact composition of the surface film, however, is highly dependent upon the electrolyte composition. Therefore, both $\mathrm{Mg}^{0}$ and $\mathrm{Mg}^{2+}$ compounds containing $\mathrm{F}, \mathrm{S}, \mathrm{C}, \mathrm{O}$ coexist in the $\mathrm{Mg}$ deposition from the $\mathrm{Mg}(\mathrm{TFSI})_{2} /$ diglyme electrolyte with the data strongly suggesting that the $\mathrm{Mg}$ compounds largely originate from the reaction of the deposited $\mathrm{Mg}^{0}$ with the TFSI ${ }^{-}$anions. The likely reason why these compounds are not evident in the XRD patterns is because they are amorphous (Fig. S2). Notably, several studies ${ }^{11-12}$ have shown that ethers are stable with $\mathrm{Mg}$ metal and our previous work ${ }^{13}$ also shows that diglyme is stable against decomposition at the $\mathrm{Mg}$ metal surface.
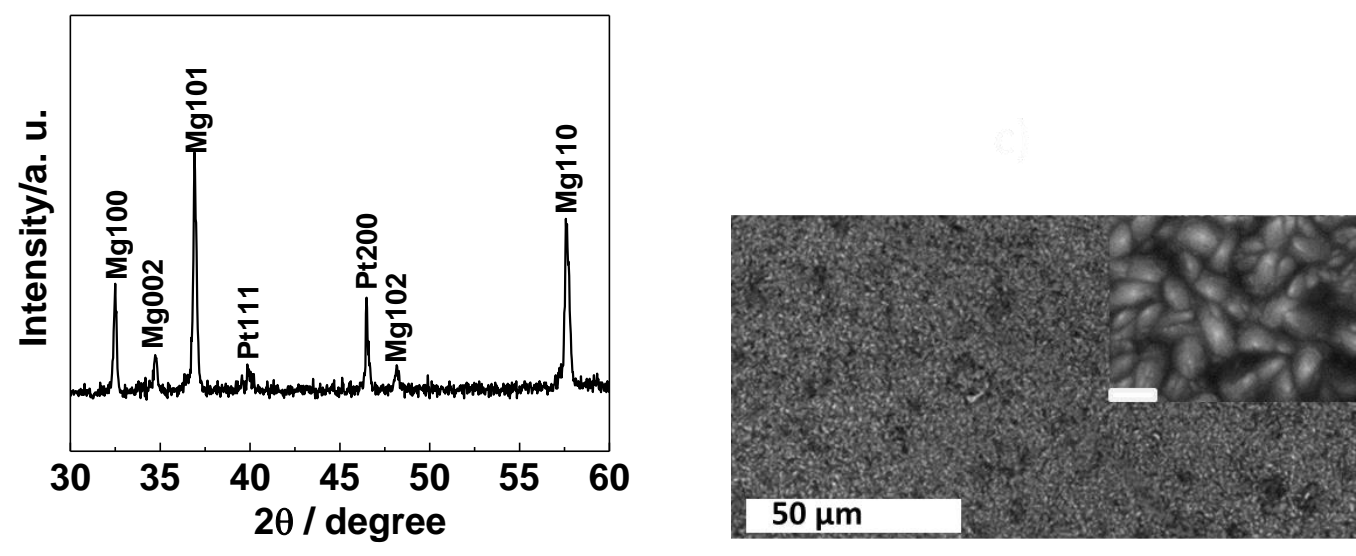

Figure S4. XRD pattern of $\mathrm{Mg}$ deposition and SEM images of $\mathrm{Mg}$ deposition in $0.4 \mathrm{M}$ $\mathrm{Mg}(\mathrm{TFSI})_{2}+0.1 \mathrm{M} \mathrm{Mg}\left(\mathrm{BH}_{4}\right)_{2} /$ diglyme. The scale bar is $2.5 \mu \mathrm{m}$ in the SEM inset. 


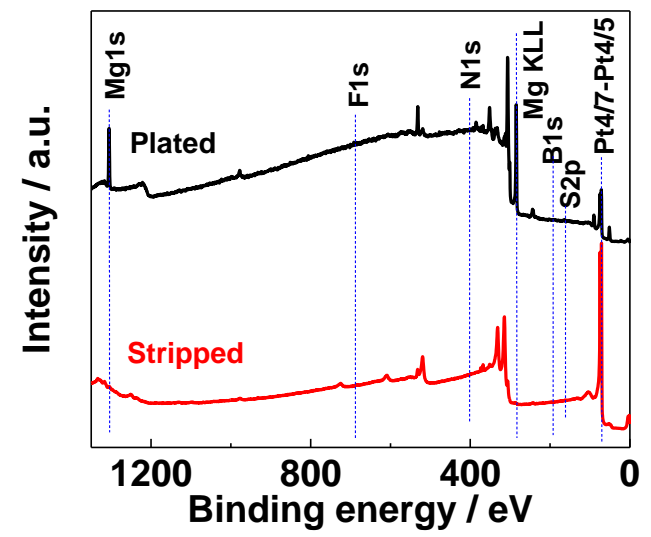

Figure S5. XPS of $\mathrm{Mg}$ electrodeposits and stripped $\mathrm{Mg}$ in $0.4 \mathrm{M} \mathrm{Mg}(\mathrm{TFSI})_{2}+0.1 \mathrm{M}$ $\mathrm{Mg}\left(\mathrm{BH}_{4}\right)_{2} /$ diglyme. 
a
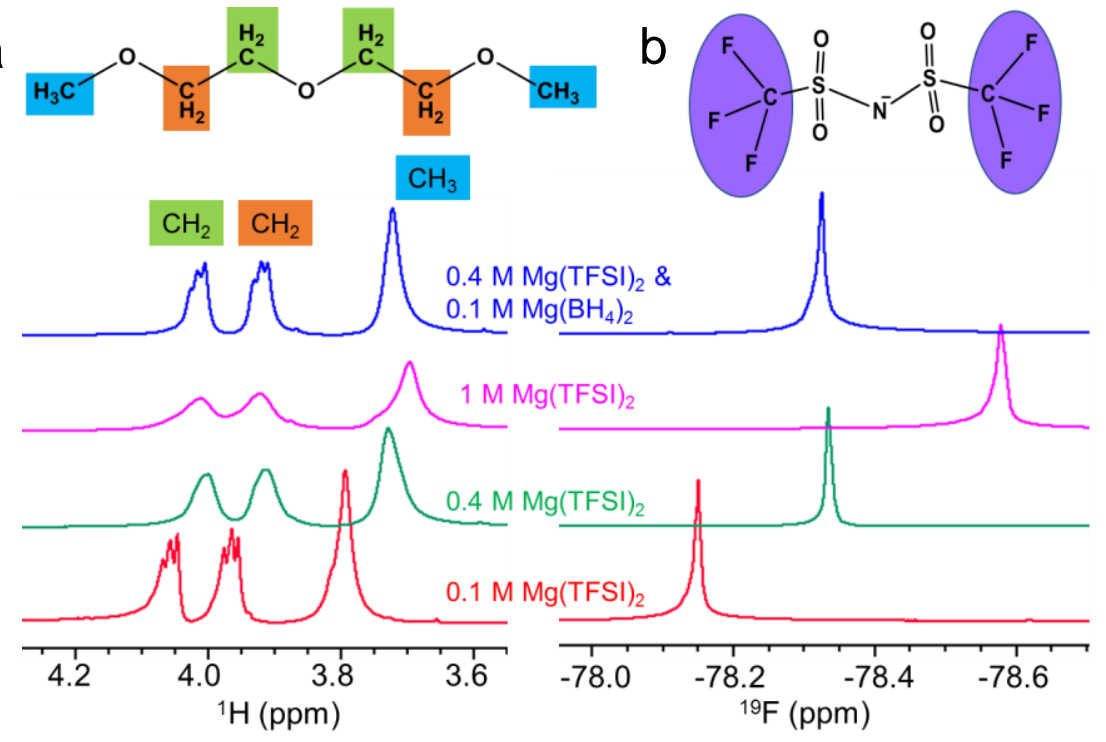

C
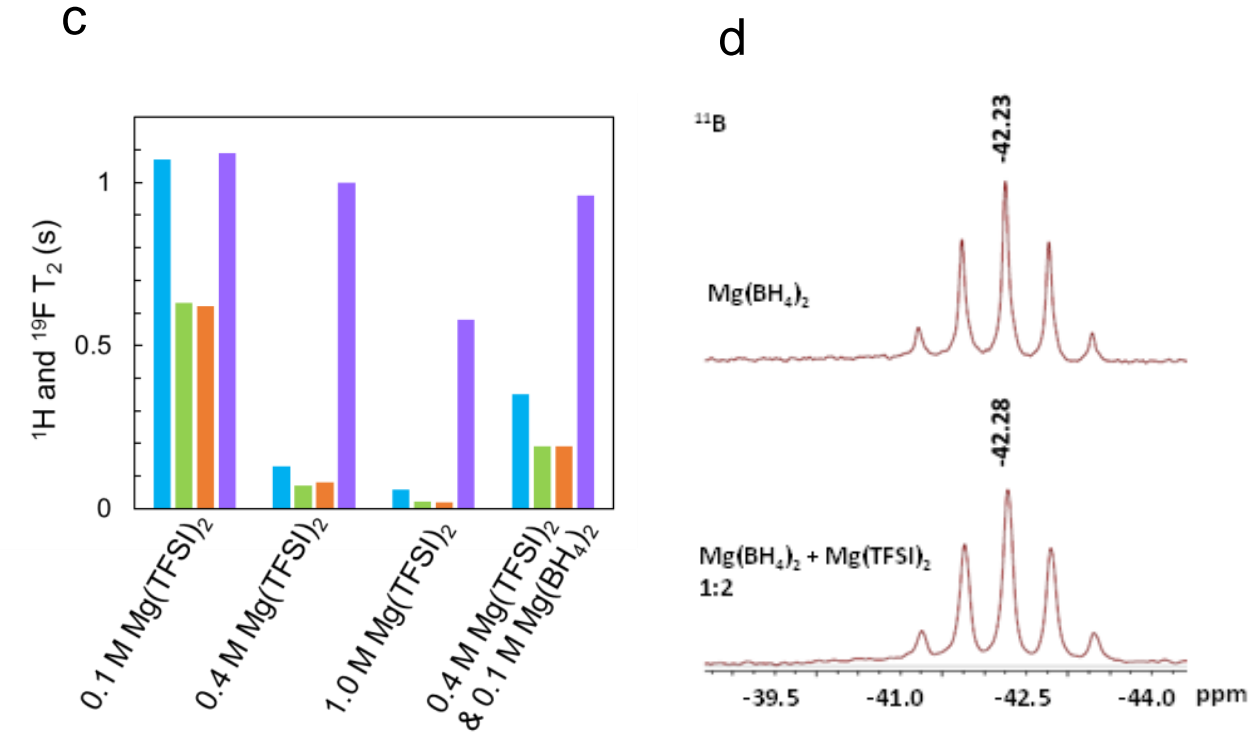

Figure S6 ${ }^{1} \mathrm{H}$ (A) and ${ }^{19} \mathrm{~F}(\mathrm{~B}) \mathrm{NMR}$ spectra, and ${ }^{1} \mathrm{H}$ and ${ }^{19} \mathrm{~F}$ NMR spin-spin relaxation time (C) of $\mathrm{Mg}(\mathrm{TFSI})_{2}-\mathrm{Mg}\left(\mathrm{BH}_{4}\right)_{2} / \mathrm{diglyme}$ at varying $\mathrm{Mg}(\mathrm{TFSI})_{2}$ concentrations. (D) ${ }^{11} \mathrm{~B}$ NMR spectra of $\mathrm{Mg}\left(\mathrm{BH}_{4}\right)_{2} /$ diglyme and $\mathrm{Mg}(\mathrm{TFSI})_{2}-\mathrm{Mg}\left(\mathrm{BH}_{4}\right)_{2} /$ diglyme. 


\section{$0.01 \mathrm{M} \mathrm{Mg}\left(\mathrm{BH}_{4}\right)_{2}$ in diglyme}

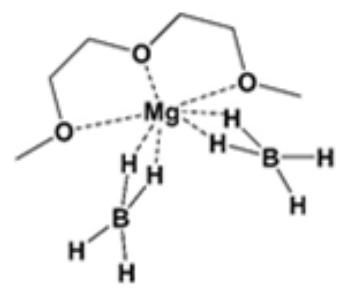

$\left[\mathrm{Mg}\left(\mathrm{BH}_{4}\right)_{2}(\right.$ diglyme $\left.)\right]$
$0.40 \mathrm{M} \mathrm{Mg}(\mathrm{TFSI})_{2}$ in diglyme

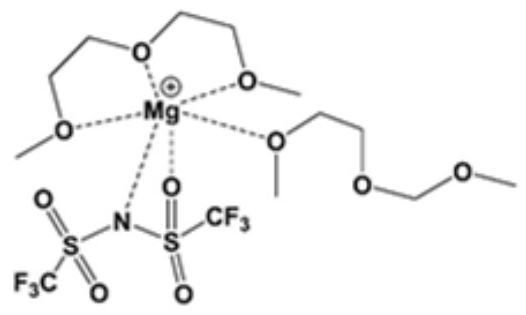

$\left[\mathrm{Mg}(\mathrm{TFSI})^{+}(\text {diglyme })_{2}\right]$
$0.40 \mathrm{M} \mathrm{Mg}(\mathrm{TFSI})_{2}$ $0.1 \mathrm{M} \mathrm{Mg}\left(\mathrm{BH}_{4}\right)_{2}$ in diglyme

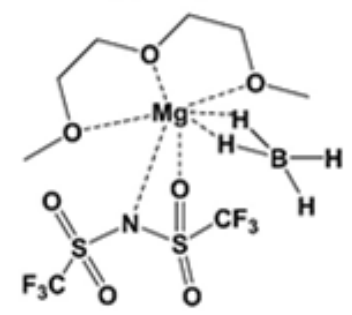

[Mg $\left(\mathrm{BH}_{4}\right)(\mathrm{TFSI})($ diglyme)]

Scheme S1. Impact of $\mathrm{BH}_{4}{ }^{-}$on the most possible solvation structure of $\mathrm{Mg}$ electrolyte. Solvation structure is derived from analysis of ${ }^{13} \mathrm{C},{ }^{1} \mathrm{H},{ }^{19} \mathrm{~F},{ }^{11} \mathrm{~B}$ NMR spectra and ${ }^{25} \mathrm{Mg}$ NMR spectra from the Ref [13] in the main text. 

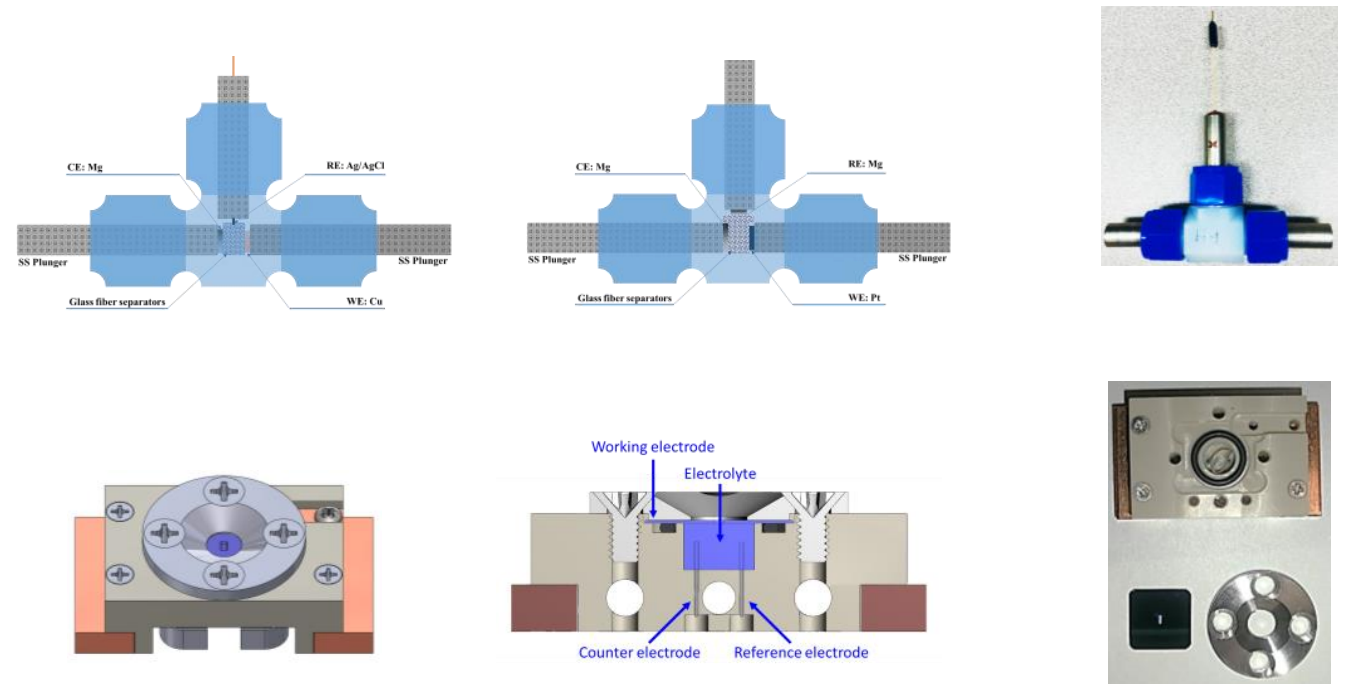

Figure S7 Typical schematic representations and photographs of three-electrode electrochemical EIS cells (upper) and XAS cells (lower) involved in this work. 


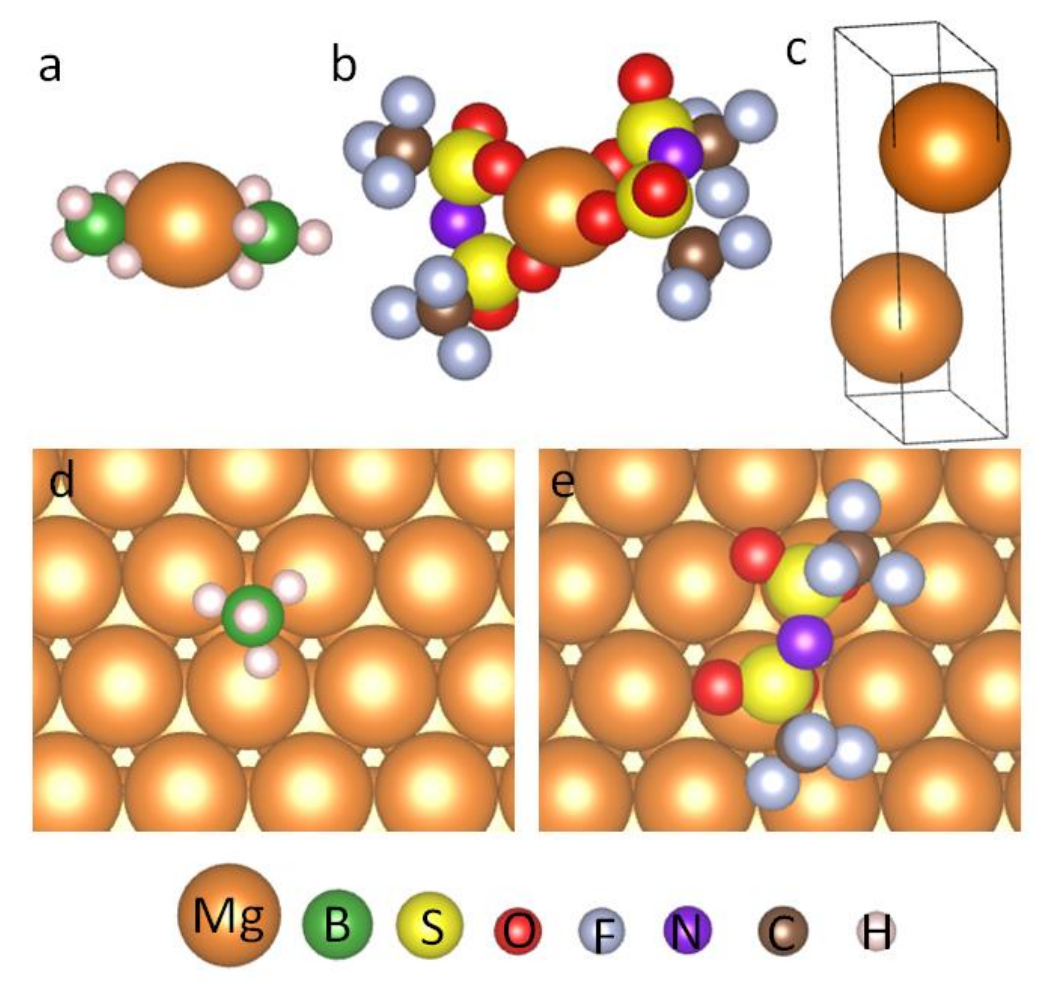

Figure S8 DFT calculations of optimized structure of (a) $\mathrm{Mg}\left(\mathrm{BH}_{4}\right)_{2}$, (b) $\mathrm{Mg}(\mathrm{TFSI})_{2}$, (c) bulk $\mathrm{Mg}$, and the interaction between $\mathrm{Mg}^{0}$ with (d) $\mathrm{BH}_{4}^{-}$, and (e) $\mathrm{TFSI}^{-}$

Periodic density functional theory (DFT) calculations were performed on a model $\mathrm{Mg}(0001)$ surface slab with five $\mathrm{Mg}$ atomic layers to correlate the interplay between the coordination energies of anions. The coordination energies, i.e., the interactions ( $E_{\text {int }}$ ) of the $\mathrm{BH}_{4}^{-}$and $\mathrm{TFSI}^{-}$anions on the $\mathrm{Mg}(0001)$ surface, were defined using the following equation:

$$
E_{\text {int }}=E_{A+M g(0001)}-E_{M g(0001)}-\frac{1}{2}\left(E_{M g A 2}-E_{M g}\right)
$$

where $E_{A+M g(0001)}$ is the total energy of the interacting anion $\left(\mathrm{BH}_{4}^{-}\right.$and $\left.\mathrm{TFSI}^{-}\right)$, $A$, on the $\operatorname{Mg}(0001)$ surface; $E_{M g(0001)}$ is the total energy of the optimized $\operatorname{Mg}(0001)$ surface slab; $E_{M g A 2}$ is the energy of neutral $\mathrm{Mg}\left(\mathrm{BH}_{4}\right)_{2}$ molecule (d) or $\mathrm{Mg}(\mathrm{TFSI})_{2}$ molecule (e) in vacuum, and $\mathrm{E}_{\mathrm{Mg}}$ is the energy of a single $\mathrm{Mg}$ atom in the $\mathrm{Mg}$ bulk material (c). Using this definition, a more negative $E_{\text {int }}$ value indicates a stronger interaction with the surface. The calculated interactions $\left(E_{\text {int }}\right)$ are $-3.24 \mathrm{eV}$ and $-2.80 \mathrm{eV}$ for $\mathrm{BH}_{4}^{-}$(a) and TFSI $^{-}$(b), respectively. The $0.44 \mathrm{eV}^{-}$higher binding energy for $\mathrm{BH}_{4}^{-}$ suggests a stronger interaction of $\mathrm{BH}_{4}^{-}$with the $\mathrm{Mg}$, indicating a thermodynamically more favorable coordination interaction between $\mathrm{BH}_{4}^{-}$and the $\mathrm{Mg}$ surface compared to TFSI $^{-}$, likely due to relatively higher charge density of the former anion. It needs to be pointed out that the potential instability of $\mathrm{BH}_{4}^{-}$in vacuum presents challenges for accurate calculation of the interaction energy, further investigation is still needed to confirm this. 

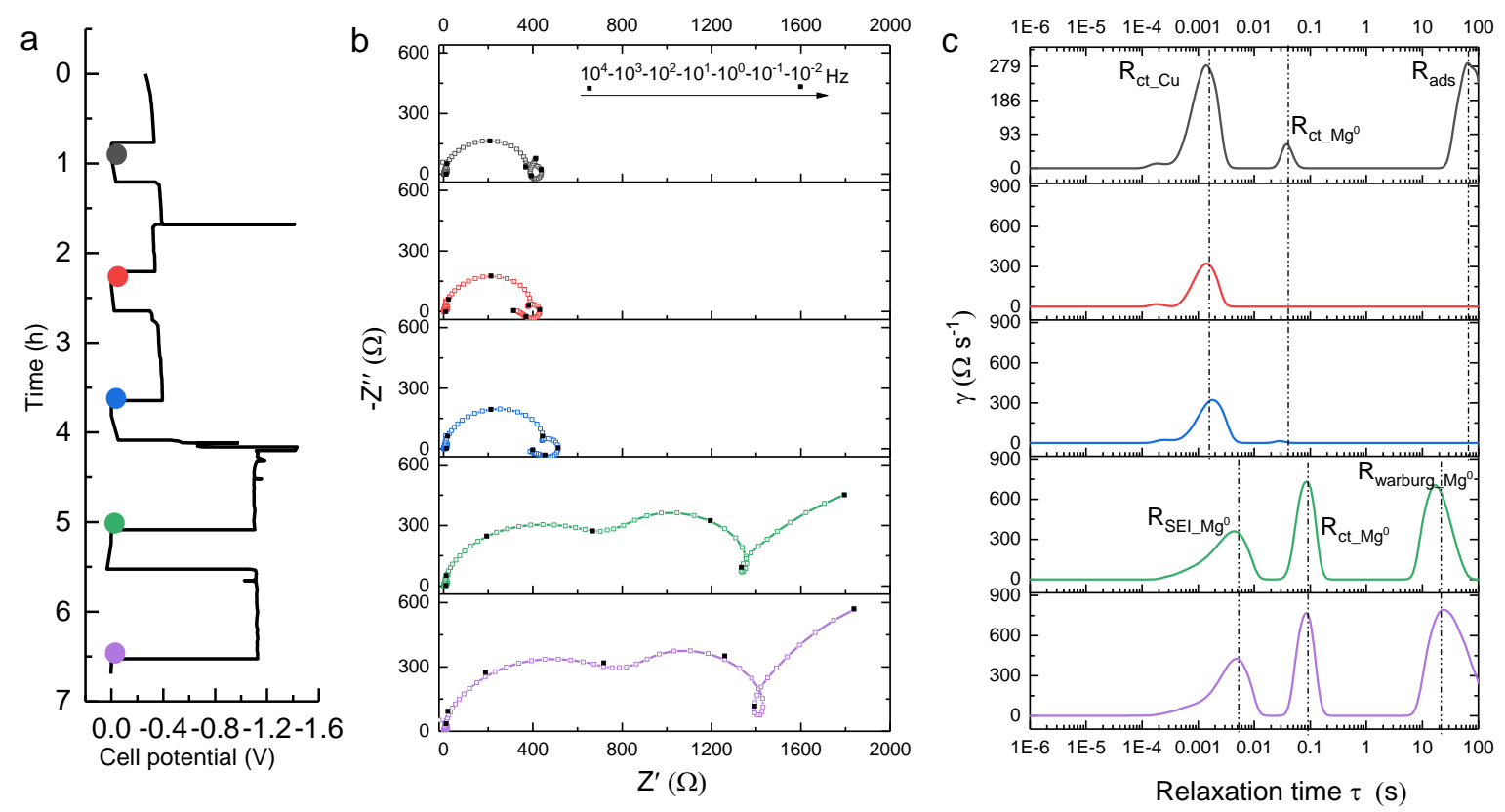

Figure S9 Occurrence of passivation driven by adsorption of active $\mathrm{Mg}$ cation clusters without $\mathrm{BH}_{4}^{-}$. Operando EIS evolution and corresponding distribution of relaxation times upon galvanostatic electrodeposited $\mathrm{Mg}$ onto $\mathrm{Cu}$ at $0.5 \mathrm{~mA} \mathrm{~cm}^{-2}$ in $0.4 \mathrm{M} \mathrm{Mg(TFSI)2/diglyme.} \mathrm{a)}$ discharge cell potential vs. time curve; b) evolution of recorded impedance spectra in the frequency range of $10^{6}-0.01 \mathrm{~Hz}$; c) corresponding DRT spectra. 


\section{References}

1. Wan, T. H.; Saccoccio, M.; Chen, C.; Ciucci, F., Influence of the Discretization Methods on the Distribution of Relaxation Times Deconvolution: Implementing Radial Basis Functions with DRTtools. Electrochim. Acta 2015, 184, 483-499.

2. Li, X. Y.; Nie, J., Density Functional Theory Study on Metal Bis(trifluoromethylsulfonyl)imides: Electronic Structures, Energies, Catalysis, and Predictions. The Journal of Physical Chemistry A 2003, 107 (31), 6007-6013.

3. Kresse, G.; Hafner, J., Ab initio molecular-dynamics simulation of the liquid-metal--amorphoussemiconductor transition in germanium. Physical Review B 1994, 49 (20), 14251-14269.

4. Kresse, G.; Furthmüller, J., Efficiency of ab-initio total energy calculations for metals and semiconductors using a plane-wave basis set. Computational Materials Science 1996, 6 (1), 15 50.

5. Kresse, G.; Furthmüller, J., Efficient iterative schemes for ab initio total-energy calculations using a plane-wave basis set. Physical Review B 1996, 54 (16), 11169-11186.

6. Perdew, J. P.; Burke, K.; Ernzerhof, M., Generalized Gradient Approximation Made Simple. Phys. Rev. Lett. 1996, 77 (18), 3865-3868.

7. Kresse, G.; Joubert, D., From ultrasoft pseudopotentials to the projector augmented-wave method. Physical Review B 1999, 59 (3), 1758-1775.

8. $\quad$ Ardizzone, S.; Bianchi, C. L.; Fadoni, M.; Vercelli, B., Magnesium salts and oxide: an XPS overview. Appl Surf Sci 1997, 119 (3), 253-259.

9. $\quad$ Aurbach, D.; Gofer, Y.; Lu, Z.; Schechter, A.; Chusid, O.; Gizbar, H.; Cohen, Y.; Ashkenazi, V.; Moshkovich, M.; Turgeman, R.; Levi, E., A short review on the comparison between Li battery systems and rechargeable magnesium battery technology. J. Power Sources 2001, 97-98, 28-32.

10. Aravindan, V.; Gnanaraj, J.; Madhavi, S.; Liu, H.-K., Lithium-Ion Conducting Electrolyte Salts for Lithium Batteries. Chem. Eur. J 2011, 17 ( 51), 14326-14346.

11. Lu, Z.; Schechter, A.; Moshkovich, M.; Aurbach, D., On the electrochemical behavior of magnesium electrodes in polar aprotic electrolyte solutions. J. Electroanal. Chem. 1999, 466 (2), 203-217.

12. Aurbach, D.; Gofer, Y.; Schechter, A.; Chusid, O.; Gizbar, H.; Cohen, Y.; Moshkovich, M.; Turgeman, R., A comparison between the electrochemical behavior of reversible magnesium and lithium electrodes. J. Power Sources 2001, 97-98, 269-273.

13. Shao, Y.; Liu, T.; Li, G.; Gu, M.; Nie, Z.; Engelhard, M.; Xiao, J.; Lv, D.; Wang, C.; Zhang, J.-G.; Liu, J., Coordination Chemistry in magnesium battery electrolytes: how ligands affect their performance. Sci. Rep. 2013, 3, 3130. 